\title{
Desempenho agronômico de cultivares de soja $R R$ para a região de Barretos-SP
}

\section{Agronomic performance of glyphosate-resistant soybean in Barretos-SP}

\author{
Hugo Dias Nunes ${ }^{1}$, Rogério Farinelli², Paschoal Alves Feres², Guilherme Jeppez Dias², \\ Igor Lucas Tobasi \\ ${ }^{1}$ Programa de Pós-graduação em Produção Vegetal (Agronomia), Departamento de Produção Vegetal, \\ Faculdade de Ciências Agrárias e Veterinárias, Universidade Estadual Paulista (UNESP) - \\ Jaboticabal (SP), Brasil. \\ ${ }^{2}$ Centro Universitário da Fundação Educacional de Barretos (UNIFEB) - Barretos (SP), Brasil.
}

\begin{abstract}
Resumo
A soja transgênica RR difere da convencional por possuir um gene de resistência ao herbicida glyphosate. O objetivo do trabalho foi avaliar o desempenho agronômico de cultivares de soja RR na região de Barretos-SP, safra 2013/14. O experimento foi conduzido no delineamento em blocos ao acaso com 10 tratamentos (cultivares de soja RR) e 4 repetições, a semeadura foi realizada em 6/12/2013, sendo cada parcela constituída por 5 linhas espaçadas de $0,5 \mathrm{~m}$ por $5 \mathrm{~m}$ de comprimento. Avaliaram-se o número de dias para o florescimento, a área foliar, a matéria seca da parte aérea, número de dias para maturação fisiológica, a altura de planta, a altura de inserção da primeira vagem, o número de vagens por planta e de grãos por vagem, a massa de 100 grãos e a produtividade de grãos. Os dados foram submetidos à análise de variância, pelo teste $\mathrm{F}(\mathrm{p}<0,05 \%)$. As médias dos tratamentos foram comparadas pelo teste Tukey ( $<<0,05 \%$ ). A cultivar PIONEER 98Y38 apresentou 46 dias para florescimento e 112 dias para maturação, e a CD 2723 PRO, 95 dias para maturação. A cultivar PIONEER 97R01 apresentou a maior área foliar. A cultivar SYN 9078 RR apresentou maior valor de matéria seca da parte aérea. A cultivar PIONEER 98Y30 apresentou a maior altura de planta. A cultivar mais produtiva foi a PIONEER 97R01 com $1.771 \mathrm{~kg} \mathrm{ha}^{-1}$. Os resultados das produtividades foram baixos em virtude das condições climáticas adversas, principalmente nos estádios fenológicos de formação de vagens e enchimento de grãos.
\end{abstract}

Palavras-chave: genótipos; Glycine max; produtividade de grãos; resistência; transgenia.

\begin{abstract}
The transgenic soybean RR differs from conventional soybeans by having a gene for resistance to glyphosate. This work aimed to evaluate the agronomic performance of soybean RR (Roundup Ready) on the region of Barretos-SP, during the 2013/2014 crop season. The experimental design was arranged in complete randomized blocks and 10 treatments (soybean RR) with four replications. The sowing was on $06 / 12 / 2013$ and the plots were 5 rows spaced by $0.50 \mathrm{~m}$ and $5 \mathrm{~m}$ of length. It was evaluated the number of days to flowering, the leaf area, the dry matter of the aerial part, number of days to maturity, the plant height, the pods insertion, number of pods per plant and seeds per pod, the mass of 100 grains and grain yield. Data were analyzed using the F test $(\mathrm{p}<0,05 \%)$. The means of treatments were compared through Tukey test $(\mathrm{p}<0,05 \%)$. The soybean cultivar PIONEER 98Y38 had 46 days until flowering and 112 days until maturity, and the CD PRO 2723 had 95 days until maturity. The soybean cultivar PIONEER 97R01
\end{abstract}

Autor para correspondência: Hugo Dias Nunes - Via de acesso Prof. Paulo Donato Castellane, s/n CEP: 14884-900 - Jaboticabal (SP), Brasil - E-mail: hugooguh_dn@hotmail.com

Recebido em: 11 de abril de 2017

Aceito para publicação em: 01 de agosto de 2017

http://dx.doi.org/10.4322/1980-0029.022017 
achieved the highest leaf area. SYN 9078 RR achieved the highest dry matter of the aerial part. PIONEER 98Y30 had the highest plant height. The most productive soybean cultivar was the PIONEER 97R01 with $1.771 \mathrm{~kg} \mathrm{ha}^{-1}$. The results of the yields were low due to adverse weather conditions, especially in the growth stages of pod formation and grain filling.

Keywords: genotypes; Glycine max; grain yeld; resistance; transgenic.

\section{Introdução}

A cultura da soja (Glycine max (L.) Merril) é uma das culturas mais cultivadas ao redor de todo o mundo, fato este devido aos altos teores de proteína e óleo, de $40 \%$ e $20 \%$, respectivamente, além do alto potencial produtivo de grãos (SILVA; FREITAS, 2008).

As características quantitativas, como componentes do rendimento (número de vagens por planta, número de grãos por vagem e massa dos grãos), altura de planta, duração do ciclo (KUMAGAI; SAMESHIMA, 2014) e produtividade, são as mais importantes na escolha das cultivares para cultivo, sendo as mais influenciadas pelo manejo (PEIXOTO et al., 2000).

Em estudos de avaliação do desempenho de cultivares de soja numa determinada região, é de suma importância a determinação da altura das plantas e da altura de inserção da primeira vagem, visando à realização da prática da colheita de forma eficiente, além dos componentes de produção, que influenciam diretamente a obtenção de alta produtividade de grãos (REZENDE; CARVALHO, 2007).

Lemos et al. (2011), avaliando o desempenho de cultivares de soja nas safras 2002/2003, 2003/2004 e 2004/2005, observaram, na maioria das cultivares estudadas, produtividade acima de $3.000 \mathrm{~kg} \mathrm{ha}^{-1}$, nas safras 2002/2003 e 2004/2005. Porém, nas três safras agrícolas, destacaram as cultivares IAC 22, BRS 133 e BRS 156.

A soja geneticamente modificada apresenta alguns benefícios, como: eficiência de controle e flexibilidade de manejo em pós-emergência, dispensa da aplicação de herbicida em pré-emergência, facilidade de adoção da semeadura direta, melhor aproveitamento da área de cultivo, com aumento da produtividade em razão do melhor controle de plantas daninhas, produção mais homogênea e estável, além de ser uma tecnologia de menor custo de produção (MENEGATTI; BARROS, 2007).

Levantamento da safra brasileira de soja de julho de 2014, realizado pela Companhia Nacional de Abastecimento (CONAB), mostrou que na safra 2013/14 a produção foi de 86.273,2 mil toneladas, representando um incremento de 5,9\% em relação à safra 2012/13. Essa produção deriva de uma área cultivada totalizando 30.110,2 mil hectares, sendo que a maior área utilizada com essa oleaginosa foi na região Centro-Oeste, com 13.883,4 mil hectares (CONAB, 2014).

Nesse sentido de crescente ganho em produtividade de soja, o Brasil vem sendo promessa no fornecimento de soja para atender à demanda mundial, cujo crescimento médio nos últimos 40 anos é cerca de cinco milhões de toneladas por ano (GUIMARÃES et al., 2008), atentando-se para as diferentes épocas de semeadura, para as diversas cultivares existentes, devido às diferenças climáticas de cada ano agrícola (PELUZIO et al., 2010).

Dentro dos programas de melhoramento genético da soja, o principal destaque é o uso da biotecnologia, com o surgimento da soja geneticamente modificada (soja transgênica). A primeira soja transgênica lançada comercialmente (soja RR), obtida com a transformação genética de plantas através da engenharia genética, difere da soja convencional por possuir um gene que expressa resistência (gene cp4-epsps) ao herbicida de ação total denominado de glyphosate. A introdução desse gene facilitou o controle das plantas daninhas, e seu uso se generalizou em algumas regiões, quando, ao mesmo tempo, surgiram reações com críticas à segurança dessa nova tecnologia (SILVEIRA; RESENDE, 2010).

Em virtude do crescente uso e adição de cultivares de soja RR, torna-se de suma importância a avaliação das características agronômicas e produtivas de cultivares comerciais de soja transgênica visando recomendações regionalizadas, permitindo mais segurança aos agricultores.

O objetivo do estudo foi avaliar o desempenho agronômico de cultivares de soja RR na safra 2013/14 na região de Barretos-SP. 


\section{Material e Métodos}

O experimento foi desenvolvido durante a safra 2013/2014, com data de semeadura 6/12/2013, na área experimental localizada na fazenda da prefeitura municipal da cidade de Barretos-SP. Com coordenadas geográficas de latitude $20^{\circ} 33^{\prime} 26^{\prime \prime}$ Sul e longitude $48^{\circ} 34^{\prime} 04^{\prime \prime}$ 'Oeste a uma altitude de 530 metros.

O clima da região, segundo a classificação de Köppen, é Aw, ou seja, com inverno seco e moderado, e verão quente e chuvoso.

$\mathrm{O}$ índice pluviométrico obtido na filial da Coopercitrus da cidade de Barretos, SP, mostrou que no mês de janeiro de 2013 houve um acúmulo de $298 \mathrm{~mm}$, já, em janeiro de 2014, apenas $73 \mathrm{~mm}$. Esta grande diferença afetou significativamente o rendimento da cultura da soja na região norte do Estado de São Paulo.

As cultivares de soja RR utilizadas foram: BMX Potência RR (BRASMAX), NA 5909 RR (Nidera Sementes), CD 250 RR (Coodetec), CD 2723 PRO (Coodetec), CD 2680 (Coodetec), SYN 1059 RR (Syngenta Seeds), SYN 9078 RR (Syngenta Seeds), PIONEER 97R01 (Pioneer), PIONEER 98Y30 (Pioneer) e TMG 7262 (Tropical Melhoramento Genético).

O solo da área experimental corresponde ao Latossolo Vermelho distrófico, textura argilosa (OLIVEIRA et al., 1999).

O sistema de manejo de solo empregado foi o convencional, utilizando grade aradora, aração com arado de discos e duas gradagens niveladoras. Na adubação mineral, utilizou-se semeadora/adubadora a fim de distribuir o adubo formulado 02-20-10+micronutrientes na dose de $340 \mathrm{~kg} \mathrm{ha}^{-1}$. A semeadura foi feita manualmente, distribuindo-se 22 sementes $\mathrm{m}^{-1}$, perfazendo uma população inicial de 440 mil plantas ha-1.

O delineamento experimental foi do tipo blocos ao acaso com 10 tratamentos (cultivares de soja RR) e 4 repetições. As parcelas experimentais constituíram-se de 5 linhas espaçadas a $0,50 \mathrm{~m}$ entre si e com 5,0 m de comprimento e $1 \mathrm{~m}$ entre parcelas, totalizando cada parcela $10 \mathrm{~m}^{2}$ e área útil de cada parcela sendo as 3 linhas centrais.

Depois da instalação do experimento, as parcelas de soja foram conduzidas de acordo com os procedimentos técnicos necessários a fim de mantê-las livres da interferência de plantas daninhas, insetos-praga e doenças.
Durante o desenvolvimento das cultivares de soja RR, foram realizadas as seguintes avaliações: Florescimento: número de dias compreendido entre a emergência das plântulas até $50 \%$ das plantas no estádio R1. Área foliar $\left(\mathrm{cm}^{2}\right)$ : determinou-se no estádio R2 (florescimento pleno) em três trifólios localizados no terço médio de dez plantas, utilizando a Equação 1 a seguir (MORAES et al., 2013):

$A F=C x L$

Em que: $\mathrm{AF}$ é a área foliar $\left(\mathrm{cm}^{2}\right), \mathrm{C}$ é o maior comprimento do limbo foliar $(\mathrm{cm})$ e L é a maior largura do limbo foliar $(\mathrm{cm})$.

Matéria seca da parte aérea $\left(\mathrm{g} \mathrm{planta}^{-1}\right)$ : determinou-se mediante a coleta de 10 plantas no estádio R2, eliminando-se o sistema radicular. Posteriormente as plantas foram colocadas em estufa de circulação forçada de ar a $60-70^{\circ} \mathrm{C}$ por 72 horas para posterior pesagem. Maturação fisiológica: número de dias compreendido entre a emergência das plântulas até $50 \%$ das plantas no estádio R8, ou seja, maturação plena.

No final do ciclo fisiológico, foram coletadas 10 plantas por parcela ao acaso na área útil, objetivando avaliar os componentes morfológicos e produtivos, que foram os seguintes: Altura de plantas $(\mathrm{cm})$ : determinou-se, utilizando régua graduada em centímetros, a distância compreendida entre a superfície do solo e a extremidade apical da haste principal de cada planta. Altura de inserção da primeira vagem $(\mathrm{cm})$ : determinou-se, utilizando régua graduada em centímetros, a distância do nível do solo (colo da planta) à inserção da primeira vagem. Número de vagens por planta: fornecida pela relação entre número total de vagens e o número total de plantas da amostra. Número de grãos por vagem: deu-se pela relação entre o número total de grãos e o número total de vagens. Massa de 100 grãos: determinou-se através da contagem de 2 sub-amostras de 100 grãos coletados ao acaso por parcela experimental e, a seguir, realizaram-se as pesagens, com correção do teor de $\mathrm{H}_{2} \mathrm{O}$ a $13 \%$. Produtividade de grãos $\left(\mathrm{kg} \mathrm{ha}^{-1}\right)$ : realizou-se colhendo as plantas da área útil de cada parcela experimental (3 linhas centrais, descartando $0,50 \mathrm{~cm}$ nas extremidades), com posterior trilha mecânica e pesagem dos grãos, sendo os dados obtidos transformados em $\mathrm{kg} \mathrm{ha}^{-1}$, a $13 \%$ de umidade determinada por meio do método da estufa a $105^{\circ} \mathrm{C} \pm 3^{\circ} \mathrm{C}$ por 24 horas (BRASIL, 1992). 
Os dados coletados foram submetidos à análise de variância, utilizando o teste $\mathrm{F}$, e as médias dos tratamentos comparadas pelo teste Tukey a $5 \%$ de probabilidade com auxílio do programa estatístico SISVAR (FERREIRA, 2011).

\section{Resultados e Discussão}

O número de dias para florescimento bem como a maturação fisiológica foram prejudicados pelas condições ambientais desfavoráveis, como altas temperaturas e baixa pluviosidade ocorrida na região.

Em explicação aos efeitos negativos causados pela baixa pluviosidade durante a condução do presente estudo, Ruviaro et al. (2011) afirmam que a água é fundamental para que a planta expresse seu potencial de resposta a todo manejo e tecnologia empregada em qualquer cultura cultivada, já que, em exemplo, o uso de irrigação está diretamente relacionado à expressão do potencial da cultura. Isso ocorre porque a água está presente em vários processos bioquímicos e fisiológicos da planta (DU et al., 2015).

Mesmo assim, a cultivar PIONEER 98 Y38 apresentou 46 dias para florescimento e 112 dias para maturação.

A cultivar CD2723 PRO apresentou 95 dias para maturação e 36 dias para florescimento, precedida pelas cultivares BMX Potência RR, NA 5909 RR, CD 2680 e SYN 1059 com 96 dias para maturação e 37, 27, 34 e 27 dias para florescimento, respectivamente (Tabela 1).

Existe uma tendência na preferência dos produtores pelas cultivares de ciclo mais precoce por ficarem menos tempo no campo e assim possibilitar o escape da ação do patógeno causador da ferrugem asiática da soja (ESPINDOLA et al., 2008). Outro fator para a escolha de cultivares precoces é a possibilidade do cultivo de milho na segunda safra (safrinha).

As cultivares BMX Potência RR, CD 250 RR, SYN 1059 RR, SYN 9078 RR, PIONEER 97R01 e TMG 7262 apresentaram os maiores valores médios para a área foliar. Já os maiores valores de matéria seca da parte aérea foram das cultivares BMX Potência RR, SYN 9078 RR, PIONEER 97R01, PIONEER 98Y30 e TMG 7262 (Tabela 1).

Os valores de área foliar das cultivares PIONEER 97R01 e BMX Potência RR estão entre os maiores. Sendo 62 e $56,7 \mathrm{~cm}^{2}$, respectivamente. Possuindo assim, uma das maiores áreas fotossintéticas no estádio R2 (florescimento pleno).

Barros et al. (2011) ressaltam que os valores muito baixos de altura de plantas refletem em baixa produtividade devido a menor área fotossintética, por outro lado, evidenciam a redução de incidência de doenças devido a menor formação de microclima e menor perda na colheita por acamamento.

A análise do crescimento pode ser realizada com base na quantificação da matéria seca, que é considerada uma importante ferramenta para

Tabela 1. Florescimento $(\mathrm{F})$, área foliar $(\mathrm{AF})$, matéria seca da parte aérea (MS) e maturação fisiológica (MF) de cultivares de soja RR. Barretos, SP, 2014.

\begin{tabular}{|c|c|c|c|c|}
\hline Cultivares & $\begin{array}{l}\text { F (dias após } \\
\text { emergência) }\end{array}$ & ${ }^{1} \mathrm{AF}\left(\mathrm{cm}^{2}\right)$ & MS (g planta $\left.{ }^{-1}\right)$ & $\begin{array}{c}\text { MF (dias após } \\
\text { emergência) }\end{array}$ \\
\hline BMX Potência RR & 37 & $56,7 \mathrm{ab}$ & $6,8 \mathrm{abc}$ & 96 \\
\hline NA 5909 RR & 27 & $36,3 \mathrm{c}$ & $4,8 \mathrm{~cd}$ & 96 \\
\hline CD $250 \mathrm{RR}$ & 27 & $49,6 \mathrm{abc}$ & $3,8 \mathrm{~d}$ & 98 \\
\hline CD 2723 PRO & 36 & $45,3 \mathrm{bc}$ & $5,5 \mathrm{bcd}$ & 95 \\
\hline CD 2680 & 34 & $47,2 \mathrm{bc}$ & $5,0 \mathrm{~cd}$ & 96 \\
\hline SYN 1059 RR & 27 & $50,2 \mathrm{ab}$ & $4,1 \mathrm{~cd}$ & 96 \\
\hline SYN 9078 RR & 44 & $50,2 \mathrm{ab}$ & $8,6 \mathrm{a}$ & 107 \\
\hline PIONEER 97R01 & 37 & $62,0 \mathrm{a}$ & 7,9 ab & 97 \\
\hline PIONEER $98 Y 30$ & 46 & $47,6 \mathrm{bc}$ & $6,7 \mathrm{abc}$ & 112 \\
\hline TMG 7262 & 36 & $48,7 \mathrm{abc}$ & $6,3 \mathrm{abcd}$ & 97 \\
\hline Teste F & -- & $5,75 * *$ & $7,54 * *$ & -- \\
\hline Média & 35 & 49,4 & 5,9 & 99 \\
\hline CV $(\%)$ & -- & 11,41 & 19,35 & -- \\
\hline
\end{tabular}

${ }^{1}$ Médias seguidas de letras distintas diferem entre si pelo teste de Tukey a $5 \%$ de probabilidade. $* *$ Significativo a $1 \%$ de probabilidade pelo teste $\mathrm{F}$, respectivamente. 
estudar o comportamento de diferentes materiais genéticos; a maioria dos processos fisiológicos que afetam o rendimento de uma cultura está relacionada com esse caráter (BENICASA, 2003). A restrição de fotoassimilados pode afetar o crescimento da planta e refletir nos valores de altura da planta e número de nós, além também de prejudicar a fixação biológica de nitrogênio, pois a soja é incluída em sistema de produção sustentável, visando incremento de $\mathrm{N}$ ao solo através da fixação simbiótica (SINCLAIR; VADEZ, 2012)

Trabalhando com diferentes formulações e duas cultivares de soja geneticamente modificada (CD 214 RR e M-SOY 8008 RR) para resistência ao herbicida glyphosate, Correia e Durigan (2007) afirmaram que as formulações do glyphosate não alteraram o acúmulo de matéria seca na parte aérea das plantas.

A cultivar SYN 9078 RR apresentou um dos maiores valores em altura de inserção da primeira vagem com $8,3 \mathrm{~cm}$. No entanto, os resultados obtidos pelas demais cultivares, bem como a média geral do experimento, foram baixos, o que pode gerar perdas significativas no momento da colheita (Tabela 2). Pois, de acordo com Rezende e Carvalho (2007), alturas de inserções da vagem de, pelo menos, 10 a $12 \mathrm{~cm}$ tornam-se adequadas à mecanização da colheita. Porém, para a maioria das lavouras de soja, a altura de inserção da vagem mais satisfatória está em torno de $15 \mathrm{~cm}$, embora as colhedoras mais modernas possam efetuar a colheita com plantas apresentando altura de inserção em torno de $10 \mathrm{~cm}$ (HEIFFIG; CÂMARA, 2006).

As cultivares PIONEER 98Y30, PIONEER 97R01 e SYN 9078 RR diferiram significativamente das demais, apresentando a maior altura de planta. Plantas de soja que apresentam altura menor que $100 \mathrm{~cm}$ são mais resistentes ao acamamento e possibilitam menor perda de vagens na colheita.

Os fatores ambientais ou de práticas culturais que afetam a altura de planta podem influenciar também a altura da inserção da primeira vagem (ESPINDOLA et al., 2008).

As ausências de condições climáticas ideais também influenciaram diretamente estas características morfológicas, sendo que as cultivares precoces (NA 5909 RR, CD 250 RR e SYN 1059 RR) foram as mais afetadas negativamente, apresentando as menores alturas de plantas e, consequentemente, menores inserções de vagens.

Não ocorreu grande variação dos resultados do número de grãos por vagem, tendo uma proximidade de 2,0 grãos por vagem. Tal característica é fortemente influenciada pelo fator genético. Nos programas de melhoramento mais modernos, são selecionadas plantas de soja e genótipos a fim de produzirem 2 a 3 óvulos por legume. Comparando a outra leguminosa de importância econômica, o feijão, há uma grande variação de genótipos e cultivares que possuem a capacidade de formar de 4 a 7 grãos por vagem.

Tabela 2. Altura de planta (AP), altura de inserção de primeira vagem (AI), número de vagens por planta (NVP) e número de grãos por vagem (NGV) de cultivares de soja RR. Barretos, SP, 2014.

\begin{tabular}{|c|c|c|c|c|}
\hline \multirow{2}{*}{ Cultivares } & ${ }^{1} \mathbf{A P}$ & AI & NVP & NGV \\
\hline & \multicolumn{2}{|c|}{ 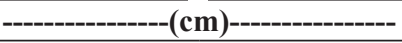 } & \multicolumn{2}{|c|}{--------- $\left(n^{0}\right)--------$} \\
\hline BMX Potência RR & $43,6 \mathrm{bc}$ & $5,6 \mathrm{~b}$ & $28,2 \mathrm{a}$ & $2,1 \mathrm{ab}$ \\
\hline NA 5909 RR & $39,0 \mathrm{c}$ & $6,5 \mathrm{ab}$ & $22,2 \mathrm{a}$ & $1,9 \mathrm{ab}$ \\
\hline CD $250 \mathrm{RR}$ & $39,8 \mathrm{c}$ & $5,8 \mathrm{~b}$ & $15,8 \mathrm{a}$ & $1,9 \mathrm{ab}$ \\
\hline CD 2723 PRO & $39,8 \mathrm{c}$ & $6,3 \mathrm{ab}$ & $18,8 \mathrm{a}$ & $2,1 \mathrm{ab}$ \\
\hline CD 2680 & $38,1 \mathrm{c}$ & $5,8 \mathrm{ab}$ & $24,3 \mathrm{a}$ & $2,2 \mathrm{a}$ \\
\hline SYN 1059 RR & $39,3 \mathrm{c}$ & $5,2 \mathrm{~b}$ & $23,1 \mathrm{a}$ & $2,0 \mathrm{ab}$ \\
\hline SYN 9078 RR & $49,6 \mathrm{ab}$ & $8,3 \mathrm{a}$ & $27,6 \mathrm{a}$ & $2,0 \mathrm{ab}$ \\
\hline PIONEER 97R01 & $44,6 \mathrm{abc}$ & $7,1 \mathrm{ab}$ & $30,0 \mathrm{a}$ & $1,9 \mathrm{ab}$ \\
\hline PIONEER $98 Y 30$ & $52,4 \mathrm{a}$ & $7,4 \mathrm{ab}$ & $30,4 \mathrm{a}$ & $1,9 \mathrm{ab}$ \\
\hline TMG 7262 & $41,3 \mathrm{bc}$ & $6,8 \mathrm{ab}$ & $24,3 \mathrm{a}$ & $1,8 \mathrm{~b}$ \\
\hline Teste F & $7,69 * *$ & $3,52 * *$ & $2,03 *$ & $2,67^{*}$ \\
\hline Média & 42,7 & 6,4 & 24,5 & 2,0 \\
\hline $\mathrm{CV}(\%)$ & 8,17 & 16,89 & 27,21 & 6,72 \\
\hline
\end{tabular}

${ }^{1}$ Médias seguidas de letras distintas diferem entre si pelo teste de Tukey a $5 \%$ de probabilidade. * e ** Significativo a $5 \%$ e $1 \%$ de probabilidade pelo teste $\mathrm{F}$, respectivamente. 
A característica número de grãos por vagem é muito importante para a cultura da soja, pois é um componente que controla a produção desta cultura. Uma boa disponibilidade hídrica no estabelecimento e no estádio reprodutivo, fotoperíodo adequado, propicia maiores produções de flores, logo, maior número de vagens por planta (LIMA et al., 2009).

No que diz respeito à massa de 100 grãos, as cultivares TMG 7262 e SYN 1059 RR apresentaram $16,52 \mathrm{~g}$ e 16,23 g, respectivamente (Tabela 3 ). No presente trabalho, as cultivares Coodetec apresentaram média de peso de 100 grãos de 12,24 g. Valor superior ao da cultivar CD 219 utilizada como testemunha em experimento de genótipos de soja realizado por Espindola et al. (2008).

O peso das sementes é uma característica importante na parcela final, quanto maior a semente maior será seu peso com menor número de sementes. Tal característica também tem influência direta na produtividade de grãos e é fortemente influenciada pelo ambiente de cultivo e sua interação com o genótipo.

A disponibilidade de água é importante, principalmente, em dois períodos de desenvolvimento da soja: germinação-emergência e floração-enchimento de grãos. Durante o primeiro período, tanto o excesso quanto o déficit de água são prejudiciais à obtenção de uma boa uniformidade na população de plantas. A semente de soja necessita absorver, no mínimo, $50 \%$ de seu peso em água para assegurar boa germinação. Nessa fase, o conteúdo de água no solo não deve exceder a $85 \%$ do total máximo de água disponível e nem ser inferior a 50\% (EMBRAPA, 2010).

Em trabalho realizado por Peixoto et al. (2000), os autores observaram que a densidade de plantas de soja influencia o número total de vagem, e que esse número diminui progressivamente também em relação à época de semeadura de soja.

Sendo um dos componentes da produção da planta, o número total de vagens formadas por cultivar deve estar associado a outras variáveis, como o número de grãos por vagem, pois há grande variação genotípica. O caráter número total de grãos, estreitamente relacionado com o número total de vagens, apresenta variação semelhante, de forma que também diminui com o aumento da população (PEIXOTO et al., 2000).

A necessidade de água na cultura da soja vai aumentando com o desenvolvimento da planta, atingindo o máximo durante a floração-enchimento de grãos ( 7 a $\left.8 \mathrm{~mm} \mathrm{dia}^{-1}\right)$, decrescendo após esse período. Déficits hídricos expressivos, durante a floração e o enchimento de grãos, provocam alterações fisiológicas na planta, como o fechamento estomático e o enrolamento de folhas, e, como consequência, causam a queda prematura de folhas e de flores e abortamento de vagens, resultando, por fim, em redução do rendimento de grãos. (EMBRAPA, 2010).

As cultivares BMX Potência, NA 5909 RR, CD 2723 PRO, CD 2680, SYN 1059 RR, PIONEER 97R01 e PIONEER 98Y30 foram as que obtiveram os maiores valores significativos para produtividade de grãos. O rendimento de grãos está associado

Tabela 3. Massa de 100 grãos e produtividade de grãos de cultivares de soja RR. Barretos, SP, 2014.

\begin{tabular}{ccc}
\hline Cultivares & ${ }^{1}$ Massa 100 grãos (g) & Produtividade de grãos (kg ha $\left.^{-1}\right)$ \\
\hline BMX Potência RR & $12,7 \mathrm{ab}$ & $1.174,0 \mathrm{abc}$ \\
NA 5909 RR & $15,0 \mathrm{ab}$ & $1.314 \mathrm{abc}$ \\
CD 250 RR & $11,2 \mathrm{~b}$ & $639 \mathrm{c}$ \\
CD 2723 PRO & $13,0 \mathrm{ab}$ & $1.107 \mathrm{abc}$ \\
CD 2680 & $12,4 \mathrm{ab}$ & $1.291 \mathrm{abc}$ \\
SYN 1059 RR & $16,2 \mathrm{a}$ & $1.216 \mathrm{abc}$ \\
SYN 9078 RR & $11,7 \mathrm{ab}$ & $965 \mathrm{bc}$ \\
PIONEER 97R01 & $14,0 \mathrm{ab}$ & $1.771 \mathrm{a}$ \\
PIONEER 98Y30 & $16,0 \mathrm{ab}$ & $1.389 \mathrm{ab}$ \\
TMG 7262 & $16,5 \mathrm{a}$ & $933 \mathrm{bc}$ \\
Teste F & $3,68^{* *}$ & $3,99^{* *}$ \\
Média & 13,90 & 1.180 \\
CV (\%) & 14,61 & 25,72 \\
\hline
\end{tabular}

${ }^{1}$ Médias seguidas de letras distintas diferem entre si pelo teste de Tukey a 5\% de probabilidade. ** Significativo a $1 \%$ de probabilidade pelo teste $\mathrm{F}$, respectivamente. 
à variabilidade de fatores como a ocorrência de déficits hídricos e a relação da água no solo. Altos investimentos são aplicados em lavouras de grandes culturas, retratando a importância da demanda hídrica para o desenvolvimento completo e eficiente das plantas, principalmente em períodos de estiagem ou veranicos que prejudicam o desenvolvimento das plantas em períodos críticos de maior necessidade hídrica, como a floração, em que a maturação fisiológica de grãos corresponde a 7,5 $\mathrm{mm} \mathrm{dia}^{-1}$ (KUSS, 2006).

Além disso, o alto rendimento de grãos na cultura da soja com a presença de água pluvial ou por meio de irrigação pode estar relacionado à maior nodulação das plantas, já que a nodulação é um fator determinante na produtividade, estando relacionada a $40 \%$ do rendimento (BRANDELERO et al., 2009).

Como a semeadura das cultivares foi realizada tardiamente, afetou a produção e outras características agronômicas, fato que corrobora com Silva Neto e Silva (2010), que afirmaram que semeaduras tardias de soja originam estresses em estádios vegetativos e reprodutivos, o que leva à redução da produção.

A falta de precipitação e temperaturas muito altas, principalmente nos estádios fenológicos de formação de vagens e enchimento de grãos, influenciaram negativamente as características agronômicas e a produtividade.

\section{Conclusões}

A cultivar Pioneer 97R01, nas condições ambientais presentes durante a condução do experimento, destacou-se pelo desempenho satisfatório em área foliar, matéria seca da parte aérea, número de vagens por planta e produtividade de grãos, podendo ser indicada para cultivo na região de Barretos - SP.

\section{Agradecimentos}

Ao PIBIC (Programa Institucional de Bolsas de Iniciação Científica) pela concessão de suporte financeiro à pesquisa.

\section{Referências}

BARROS, L. S. et al. Genótipos de soja de ciclo semi precoce/médio quanto à doenças fúngicas foliares e caracteres agronômicos. Revista Enciclopédia Biosfera, v. 7, n. 12, p. 1-8, 2011.
BENICASA, M. M. P. Análise de crescimento de plantas (noções básicas). Jaboticabal: FUNEP. 2003. $42 \mathrm{p}$.

BRANDELERO, E. M.; PEIXOTO, C. P.; RALISCH, R. Nodulação de cultivares de soja e seus efeitos no rendimento de grãos. Semina: Ciências Agrárias, v. 30, n. 3, p. 581-588, 2009.

BRASIL. Ministério da Agricultura. Divisão de Sementes e Mudas. Regras para análise de sementes. Brasília: Ministério da Agricultura, 1992. $365 \mathrm{p}$.

COMPANHIANACIONAL DEABASTECIMENTO - CONAB. $9^{\circ}$ Levantamento de grãos da safra 2013/2014. Brasília: CONAB, 2013. Disponível em: $<$ http://www.conab.gov.br/OlalaCMS/uploads/ arquivos/14_06_10_12_12_37_boletim_graos junho_2014.pdf>. Acesso em: 10 jun. 2014.

CORREIA, N. M.; DURIGAN, J. C. Seletividade de diferentes herbicidas à base de glyphosate à soja RR. Planta Daninha, v. 25, n. 2, p. 375-379, 2007.

DU, T. et al. Deficit irrigation and sustainable water-resource strategies in agriculture for China's food security. Journal of Experimental Botany, v. 66, n. 8, p. 2253-2269, 2015.

EMPRESA BRASILEIRA DE PESQUISA AGROPECUÁRIA - EMBRAPA. Tecnologias de produção de soja - Região Central do Brasil - 2011. Londrina: Embrapa Soja: Sistemas de Produção, 2010. 255 p.

ESPINDOLA, S. M. C. G. et al. Avaliação do desempenho produtivo de linhagens de soja para a região do Cerrado. In: SIMPÓSIO INTERNACIONAL SAVANAS TROPICAIS, 2 ., 2008, Planaltina. Anais.... Planaltina: EMBRAPA Cerrados, 2008. p. 7.

FERREIRA, D. SISVAR software: versão 4.6. Lavras: DEX/UFLA, 2011.

GUIMARÃES, F. S. et al. Cultivares de soja [Glycine max (L.) Merril] para cultivo de verão na região de Lavras-MG. Ciência e Agrotecnologia, v. 32, n. 4, p. 1099-1106, 2008.

HEIFFIG, L. S.; CÂMARA, G. M. S. Soja: colheita e perdas. Piracicaba: ESALQ/USP, 2006. 37 p. 
KUMAGAI, E.; SAMESHIMA, R. Genotypic diferences in soybean yield responses to increasing temperature in a cool climate are related to maturity group. Agricultural and Forest Meteorology, v. 198-199, p. 265-272, 2014.

KUSS, R. C. R. Populações de plantas e estratégias de irrigação na cultura da soja. 2006. 77 f. Dissertação (Mestrado em Engenharia Agrícola) - Universidade Federal de Santa Maria, Santa Maria, 2006.

LEMOS, L. B. et al. Desempenho agronômico e produtivo de cultivares de soja em diferentes safras. Cientifica, v. 39, n. 1/2, p. 44-51, 2011.

LIMA, E. V. et al. Características agronômicas, produtivas e qualidade fisiológica da soja "safrinha" sob semeadura direta, em função da cobertura vegetal e da calagem superficial. Revista Brasileira de Sementes, v. 31, n. 1, p. 69-80, 2009.

MENEGATTI, A. L. A.; BARROS, A. L. M. Análise comparativa dos custos de produção entre soja transgênica e convencional: um estudo de caso para o Estado do Mato Grosso do Sul. Revista de Economia e Sociologia Rural, v. 45, n. 1, p. 163-183, 2007.

MORAES, L. et al. Avaliação da área foliar a partir de medidas lineares simples de cinco espécies vegetais sob diferentes condições de luminosidade. Revista Brasileira de Biociências, v. 11, n. 4, p. 381-387, 2013.

OLIVEIRA, J. B. et al. Mapas pedológicos do Estado de São Paulo: legenda expandida. Campinas: EMBRAPA Solos, 1999. 63 p.
PEIXOTO, C. P. et al. Épocas de semeadura e densidade de plantas de soja: I. Componentes da produção e rendimento de grãos. Scientia Agrícola, v. 57, n. 1, p. $89-96,2000$

PELUZIO, J. M. et al. Adaptabilidade e estabilidade de cultivares de soja em várzea irrigada no Tocantins. Revista Ciência Agronômica, v. 41, n. 3, p. 427-434, 2010.

REZENDE, P. M.; CARVALHO, E. A. Avaliação de cultivares de soja (Glycine max (L.) Merrill) para o Sul de Minas Gerais. Ciência e Agrotecnologia, v. 31, p. 1616-1623, 2007.

RUVIARO, C. et al. Comportamento da soja submetida a diferentes regimes hídricos e viabilidade da irrigação suplementar da região do Vale do Jaguari-RS. Perspectiva, v. 35, n. 131, p. 79-90, 2011.

SILVA NETO, P.; SILVA, S. A. Plantio da soja na época certa. Planaltina, DF: Embrapa Cerrados, 2010.

SILVA, P. R. F.; FREITAS, T. F. S. Biodiesel: o ônus e o bônus de produzir biocombustível. Ciência Rural, v. 38, n. 3, p. 843-851, 2008.

SILVEIRA, J. V. F.; RESENDE, L. M. Estratégias de mercado no agronegócio paranaense: soja convencional vs. transgênica. Produção, v. 20, n. 1, p. $54-65,2010$

SINCLAIR, T. R.; VADEZ, V. The future of grain legumes in cropping systems. Crop \& Pasture Science, v. 63, n. 6, p. 501-512, 2012. 